\title{
The immunomodulator, ammonium trichloro[1,2-ethanediolato-O,O']-tellurate, suppresses the propagation of herpes simplex virus 2 by reducing the infectivity of the virus progeny
}

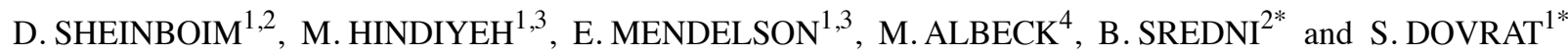 \\ ${ }^{1}$ Central Virology Laboratory, The Chaim Sheba Medical Center; ${ }^{2}$ The SAFDIÉ Cancer, AIDS and \\ Immunology Research (CAIR) Institute, The Mina and Everard Goodman Faculty of Life Sciences, \\ Bar-Ilan University, Ramat-Gan; ${ }^{3}$ Sackler Faculty of Medicine, Tel-Aviv University, Tel-Aviv; \\ ${ }^{4}$ Department of Chemistry, Faculty of Exact Sciences, Bar-Ilan University, Ramat-Gan, Israel
}

Received January 21, 2015; Accepted March 17, 2015

DOI: $10.3892 /$ ijmm.2015.2197

\begin{abstract}
Persistent investigations for the identification of novel anti-herpetic drugs are being conducted worldwide, as current treatment options are sometimes insufficient. The immunomodulator, ammonium trichloro[1,2-ethanediolato-O,O']-tellurate (AS101), a non-toxic tellurium (IV) compound, has been shown to exhibit anti-viral activity against a variety of viruses in cell cultures and in animal models. In the present study, the anti-viral activity of AS101 against herpes simplex virus (HSV)-1 and 2 was investigated in vitro. The results demonstrated that AS101 significantly restricted HSV-2induced plaque formation and reduced the infectivity of the HSV-2 yield, while HSV-1 was affected to a lesser extent. The incubation of mature HSV-1 and HSV-2 viruses with AS101 had no effect on viral infectivity, indicating that the compound interrupts de novo viral synthesis. The addition of AS101 at up to $9 \mathrm{~h}$ post-infection had almost the same effect as did the addition of the drug together with the virus (it maintained $80 \%$ of its total anti-viral capacity). Quantitative PCR and immunofluoresence staining of viral structural proteins revealed that the viral DNA and protein synthesis stages were not interrupted by the administration of AS101. By contrast, in the presence of the compound, significantly fewer viable viruses ( $\geq 2 \log$ reduction)
\end{abstract}

Correspondence to: Professor Benjamin Sredni, The Mina and Everard Goodman Faculty of Life Sciences, Bar-Ilan University, Ramat-Gan 5290002, Israel

E-mail: srednib@biu.ac.il

Dr Sara Dovrat, Central Virology Laboratory, The Chaim Sheba Medical Center, Derech Sheba 2, Tel-Hashomer, Ramat-Gan 52621, Israel

E-mail: sara.dovrat@sheba.health.gov.il

*Contributed equally

Key words: immunomodulator, herpes simplex virus 1, herpes simplex virus 2, infectivity, progeny were recovered from the AS10-treated cell cultures. Of note, when we determined the viability of the intracellular virus, formed in the presence of the compound, a less severe $(\leq 1 \log )$ effect was observed. Taken together, these data strongly suggest that AS101 primarily interferes with late stages of viral replication, such as viral particle envelopment or egress, leading to the production of a defective virus progeny.

\section{Introduction}

Herpes simplex virus (HSV) is a common human pathogen that infects orofacial mucosal surfaces (HSV-1) and genital mucosal surfaces (HSV-2) (1). Severe pathological conditions may result from infections of the cornea (keratitis) (2) or the central nervous system (encephalitis) (3), while infection in newborns or immunocompromised individuals may result in severe disseminated diseases (4). Drugs used for the treatment of HSV infections primarily belong to a group of nucleoside analogs designed to inhibit viral DNA synthesis, such as acyclovir and its derivatives. Nonetheless, resistant strains develop in immunocompromised patients, particularly among HIV-infected individuals or those who have undergone bone-marrow transplants. In these cases, highly toxic DNA polymerase inhibitors, such as foscarnet or cidofovir are administered (5). As a result, there is a need for the development of novel anti-HSV agents, particularly for compounds with a new mode of action.

Plant extracts and synthetic molecules constitute key sources for novel anti-viral drugs (6-9). Within these two categories, molecules with immunomodulating capacities are particularly promising in this regard. More specifically, previous studies have reported that the immune-response modifiers, imiquimod and resiquimod, effectively fight $\mathrm{HSV}$ infections $(8,10)$. The non-toxic ammonium, trichloro[1,2-ethanediolato-O,O']-tellurate (AS101; BioMAS Ltd., Kfar Saba, Israel), is a low molecular-weight organic compound (11) previously reported to be a potent immunomodulator both in vitro and in vivo, and has been reported to exhibit the potential for therapeutic applications (12-14). AS101 has been shown to act directly against several human 
and non-human viruses, including murine cytomegalovirus (15), HIV (16), West Nile virus (WNV) (17), avian and human influenza viruses (Mandelboim et al, personal communication) and the human papillomavirus (HPV) (18). The topical application of AS101 has been shown to be effective against genital warts caused by the HPV 6 and 11 strains; it requires a relatively short duration of treatment, triggers minimal side-effects and is associated with a low recurrence rate (18). Phase-2 clinical trials have recently begun (http://clinicaltrials.gov/show/NCT01555112), and a phase-3 clinical trial is expected to commence shortly (B. Sredni, personal communication). Since HSV infection, similar to HPV, is manifested by dermal lesions, AS101 cream may be effective against HSV lesions as well.

The primary objectives of this study were to evaluate the direct anti-viral activity of AS101 against HSV-1 and HSV-2 in a cell culture model, and to identify the stage of viral replication that is sensitive to the drug.

\section{Materials and methods}

Cells and viruses. Monkey kidney Vero cells (Cat. no. ccl-81; American Type Culture Collection, Manassas, VA, USA) were grown in Eagle's minimum essential medium-with non-essential amino acids (MEM-NAA) containing 10\% heat-inactivated fetal bovine serum (FBS). Human kidney (HK) cells (obtained from the Department of National Health and Welfare, Ottawa, ON, Canada) were grown in M199 medium containing $10 \%$ FBS. All media were supplemented with streptomycin $0.8 \mathrm{mg} / \mathrm{ml}$, penicillin $800 \mathrm{U} / \mathrm{ml}$ and mycostatin $50 \mathrm{U} / \mathrm{ml}$. The cells were cultured at $37^{\circ} \mathrm{C}$ in humidified air containing $5 \% \mathrm{CO}_{2}$. All reagents (medium and serum) were purchased from Biological Industries Israel Beit-Haemek, Ltd. (Kibbutz Beit-Haemek, Israel). HSV-1 (VR3 strain) was a kind gift from Dr A. Nahmias (Emory University School of Medicine, Atlanta, GA, USA) and HSV-2 (RL strain) was a kind gift from Dr S. Schprecher-Goldberger (Saint-Pierre University Hospital, Laboratory of Microbiology, Brussels, Belgium). The HSV-1 and HSV-2 clinical isolates were isolated from patient clinical samples submitted for HSV-1 and HSV-2 testing (the use of those samples was approved by the Helsinki Committee of the Chaim Sheba Medical Center, Ramat-Gan, Israel; 1007-14-SMC). The viruses were propagated to $>10^{7}$ plaque-forming units (PFU) per $\mathrm{ml}$ on Vero cells, as described below, aliquoted and stored at $-80^{\circ} \mathrm{C}$ until use.

Reagents. AS101 was provided by BioMAS Ltd. It was dissolved in PBS (pH 7.4) and maintained at $4^{\circ} \mathrm{C}$.

Viral stock preparation. A confluent Vero cell monolayer was infected with HSV-1 (VR), HSV-2 (RL), or HSV clinical isolates at a multiplicity of infection (MOI) of 0.01 . At $96 \mathrm{~h}$ post-infection (pi), when significant cytopathic effects (CPE) were observed, the cell cultures were frozen at $-80^{\circ} \mathrm{C}$ for $24 \mathrm{~h}$, thawed, and the supernatants were then collected and centrifuged at $400 \mathrm{x} g$ for $10 \mathrm{~min}$. The cleared supernatants were aliquoted and stored at $-80^{\circ} \mathrm{C}$. The various stocks were titrated by a standard plaque assay, as described below.

Cytotoxicity assay. The toxicity of AS101 was tested using XTT assay, performed according to the manufacturer's instruc- tions (Xenometrix AG, Allschwil, Switzerland). In brief, the Vero and HK cells were seeded at a density of $4 \times 10^{4}$ cells/well in 96-well plates and incubated for $24 \mathrm{~h}$ at $37^{\circ} \mathrm{C}$ in a $5 \% \mathrm{CO}_{2}$ incubator. After removing the growth medium (MEM-NAA containing $10 \%$ heat-inactivated FBS) various concentrations of AS101 $(1.5-30 \mu \mathrm{g} / \mathrm{ml})$ diluted in MEM-NAA medium supplemented with 5\% FBS were placed over the cells, which were incubated for an additional $48 \mathrm{~h}$. An equal volume of PBS served as the control. Before the analysis, the culture medium was replaced with fresh MEM-NAA medium, without serum and $50 \mu \mathrm{l}$ XTT reaction solution was added to each well. A mixture of culture medium and XTT reagent solution was placed in cell-free wells and served as a background (blank) control. The cells were then incubated for up to $2 \mathrm{~h}$. The absorbance of the reduced orange-colored tetrazolium salt was measured by a spectrophotometer at a wavelength of $450 \mathrm{~nm}$. Absorbance at $630 \mathrm{~nm}$, representing non-specific readings, and the blank control reading, were subtracted from all readings. Cell viability was calculated as the percentage of the mean optical density (OD) value of the controls (PBS-treated cells).

Plaque reduction assay. The plaque reduction assay was performed as previously described (19), with the following adaptations: the Vero or HK cells were seeded at a density of $10^{6}$ cells/well in a 6 -well plate $20 \mathrm{~h}$ prior to infection. The cells were infected with either clinical isolates or laboratory reference strains, at a concentration of 40-80 PFU/well (which enables the convenient counting of plaques), suspended in MEM-NAA containing $2 \%$ FBS (inoculum volume $0.2 \mathrm{ml} /$ well) and incubated $\left(1 \mathrm{~h}, 37^{\circ} \mathrm{C}, 5 \% \mathrm{CO}_{2}\right)$ with constant shaking. Following incubation, the medium was removed and the cells were washed twice with medium and overlaid with fresh medium containing $2 \%$ FBS, $0.4 \%$ (w/v) agar (Difco Laboratories, Jerusalem, Israel) and $5 \mu \mathrm{g} / \mathrm{ml}$ AS101. AS101 was added at different time points or at different concentrations, as indicated in the text below. The cells were then incubated $\left(37^{\circ} \mathrm{C}, 5 \% \mathrm{CO}_{2}\right)$ for $3-4$ days until plaques appeared, and were then fixed and stained with a fixation/staining solution containing ethanol (1.67\%), formalin (3\%) and crystal violet $(0.4 \%)$ diluted in saline. The plaques were counted over a light box after removal of the agar overlay. Differences in plaque area were determined using ImageJ software. A plaque area of 35 representative plaques from each treatment was taken for statistical analysis.

Virus yield titration by plaque assay. One day prior to infection, the HK cells $\left(10^{6}\right.$ cells/well in a 6 -well plate) were seeded in M199 medium supplemented with 10\% heat-inactivated FBS. The cells were infected with HSV-1 (VR3) or HSV-2 (RL) at an MOI of $0.1,0.5,1$ and 2 . The virus was allowed to be adsorbed for $1 \mathrm{~h}$ with constant shaking, and was then removed. The cells were washed twice with M199 medium and then overlaid with M199 medium containing 2\% FBS with or without $5 \mu \mathrm{g} / \mathrm{ml}$ AS101. At the indicated time points, the supernatants were collected, centrifuged (400 x g, $10 \mathrm{~min}$ ) and the supernatant was diluted by 10 -fold serial dilutions in culture medium supplemented with $2 \%$ FBS. To determine the intracellular virus titer, the infected cells were washed twice with fresh medium and scraped into M199 medium supplemented with $2 \%$ FBS using a rubber policeman. The suspension of the cells was then subjected to 3 cycles of freezing (liquid nitrogen) and 
Table I. Primers and probes used for the TaqMan detection of the $\mathrm{gB}$ region.

\begin{tabular}{lll}
\hline Final concentration $(\mathrm{nM})$ & \multicolumn{1}{c}{ Sequence $\left(5^{\prime} \rightarrow 3^{\prime}\right)$} & \multicolumn{1}{c}{ Primers/probes } \\
\hline 300 & AGATATCCTCTTTATCATCAGCACCA & HSV-2-Forward \\
300 & TTGTGCTGCCAAGGCGA & HSV-2-Reverse \\
200 & CGGCGGCGTTCGTTTGTCTG & HSV-2-Prob (5'-FAM, 3'-TAMRA)
\end{tabular}

gB, glycoprotein B; HSV-2, herpes simplex virus 2; 5'-FAM,FAM-6-carboxyfluorescein; 3'-TAMRA, TAMRA-6-carboxytetramethylrhodamine.

thawing (water bath at $37^{\circ} \mathrm{C}$ ), followed by centrifugation at (400 x g, $10 \mathrm{~min})$. The supernatant, containing the intracellular virus, was diluted by 10 -fold serial dilutions and titrated on the Vero cells by plaque assay.

Assay of virucidal activity. The direct effect of AS101 on HSV-1 and HSV-2 infectivity was assayed by mixing $0.05 \mathrm{ml}$ concentrated viral stock solutions containing $2.2 \times 10^{5} \mathrm{PFU} / \mathrm{ml} \mathrm{HSV}-2$ or $3.8 \times 10^{8} \mathrm{PFU} / \mathrm{ml} \mathrm{HSV-1}$ with $0.05 \mathrm{ml}$ MEM-NAA medium containing AS101 $(10 \mu \mathrm{g} / \mathrm{ml})$ or with $0.05 \mathrm{ml}$ MEM-NAA medium containing an equal volume of PBS. Both the AS101and PBS-treated viruses were incubated at $37^{\circ} \mathrm{C}$ for $2 \mathrm{~h}$. The mixture was then diluted to a concentration of 40-80 PFU/ml in MEM-NAA medium containing $2 \% \mathrm{FBS}$, and placed over the Vero cells $(0.2 \mathrm{ml}$ diluted virus per well on a 6 -well plate) for $1 \mathrm{~h}$ at $37^{\circ} \mathrm{C}$. The inoculum was then removed and the Vero cell cultures were washed twice before being overlaid with medium to allow plaque formation.

DNA extraction. DNA was extracted using the High Pure Viral Nucleic Acid kit (Roche, Manheim, Germany) according to the manufacturer's instructions. DNA was recovered in $50 \mu \mathrm{l}$ elution buffer, and $10 \mu \mathrm{l}$ samples of 10 -fold serial dilutions were quantitatively analyzed using the TaqMan real-time PCR method, as previously described (20).

Quantitative (real-time) PCR. A nucleotide segment of the glycoprotein B (gB) region (nt 139 824-139 896, accession no. NC_001798) was amplified by the use of primers and probes as described in Table I. The reaction volume of $25 \mu \mathrm{l}$ contained 12.5 $\mu$ l universal master mix (ABsolute Blue qPCR low rox mix, Cat. no. AB-4318/B; Thermo Fisher Scientific, Inc., Waltham, MA, USA) $10 \mu \mathrm{l}$ of sample DNA and primers and probes at the concentrations described in Table I. Amplification was carried out in a real-time PCR instrument ABI PRISM 7500 (Applied Biosystems, Foster City, CA, USA) with the following cycling conditions: incubation at $50^{\circ} \mathrm{C}$ for $2 \mathrm{~min}$ and denaturation at $95^{\circ} \mathrm{C}$ for $10 \mathrm{~min}$, followed by 60 amplification cycles at $95^{\circ} \mathrm{C}$. For each positive sample, the threshold cycle $(\mathrm{Ct})$ value was recorded. The $\mathrm{Ct}$ is the cycle when the fluorescence has become detectable and is in the exponential phase of amplification. The $\mathrm{Ct}$ value is inversely proportional to the log concentration of the target DNA.

Preparation of HSV DNA standards. Ten-fold serial dilutions were prepared from the commercial quantified HSV-2 DNA (Advanced Technologies, Inc., Columbia, MD, USA). The DNA stocks were serially diluted in RNase- and DNase-free water.
Standards were analyzed in triplicate and used to generate a standard curve as well as a positive control for each quantitative PCR run.

Direct and indirect immunofluorescence assays. Confluent HK tissue cultures were infected with HSV-2 at an MOI of $2 \mathrm{PFU} / \mathrm{cell}$ in the presence or absence of AS101. The cells were harvested $20 \mathrm{~h}$ pi with a rubber policeman, and samples of $2 \times 10^{6}$ cells $/ \mathrm{ml}$ were applied on glass slides using a cytocentrifuge (Shandon CytoSpin 3; Shandon, Pittsburgh, PA, USA) at $54 \mathrm{x}$ g for $4 \mathrm{~min}$. The slides were fixed with acetone, washed with PBS and subjected to immunofluorescence staining using both direct and indirect methods. Direct immunofluorescence staining was performed using a mixture of fluorescein-labeled murine monoclonal antibodies against HSV-2 140 kDa RR1 protein, HSV-2 (ICP34.5 $\alpha 38 \mathrm{kDa}$ ) and HSV-2 gB (8H349UL; Trinity Biotech PLC, Wicklow, Ireland), according to the manufacturer's instructions. Indirect immunofluorescence staining was performed using a mouse monoclonal antibody against HSV-VP-5 (SC-13525; Santa Cruz Biotechnology, Inc., Santa Cruz, CA, USA), followed by the application of FITC-labeled polyclonal rabbit anti-mouse immunoglobulins (DakoCytomation, Glostrup, Denmark).

Software. ImageJ software was used to calculate the plaque areas from the photographed 6-well plates.

Statistical analysis. The data presented are the means \pm standard deviation (SD) of triplicate measures of 3 or more experiments performed independently. Error bars represent SD. Statistical significance of the mean value was calculated using a one-sided Student's t-test. A value of $\mathrm{P}<0.05$ was considered to indicate a statistically significant difference.

\section{Results}

Effect of AS101 on HSV-1 and HSV-2 plaque formation. The effect of AS101 on cell viability was assessed by XTT assay. AS101 was tolerated at all tested concentrations (up to $30 \mu \mathrm{g} / \mathrm{ml}$ ) by both the Vero and HK cell lines (data not shown). The anti-viral activity of AS101 was manifested by a reduced plaque number and a profound effect on plaque size in the HSV-2-infected cells (Fig. 1). No visible effect was detected on either the plaque number or the size of the HSV-1-infected cells. This phenomenon was not restricted to laboratory strains and was induced by fresh clinical isolates as well. In order to verify that AS101 anti-HSV-2 activity is not cell-type specific, the experiments were performed on Vero and HK cell lines. The 
A
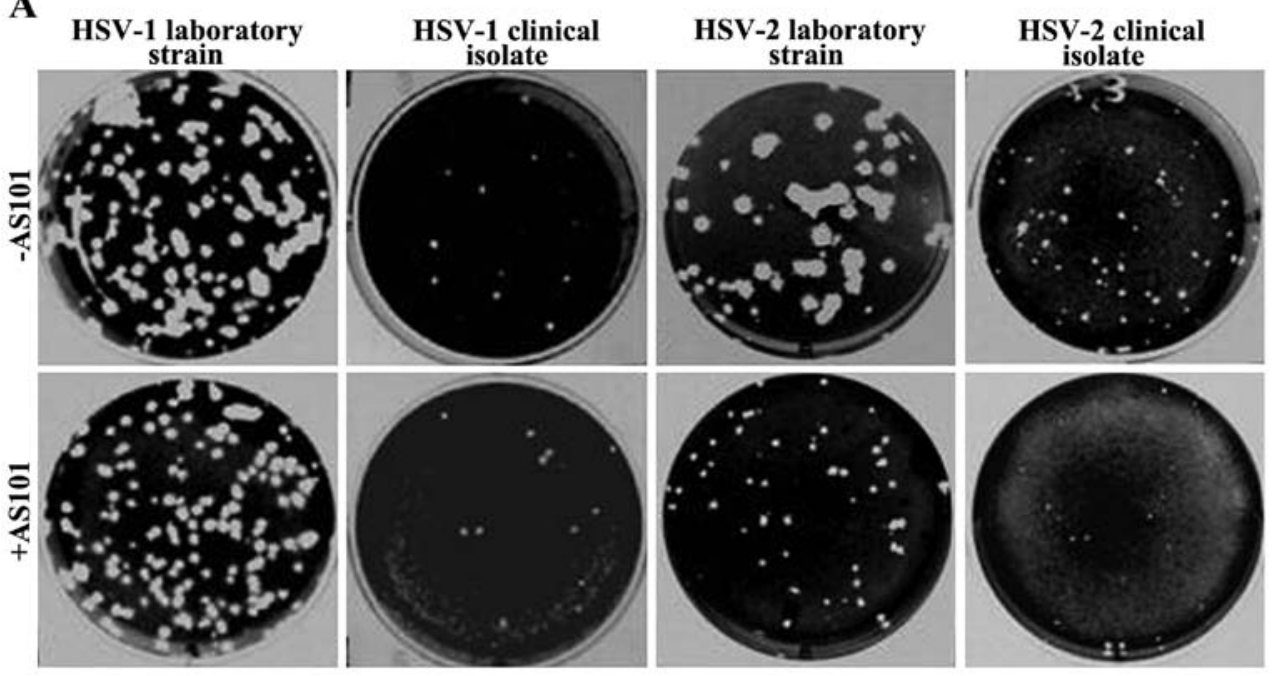

B

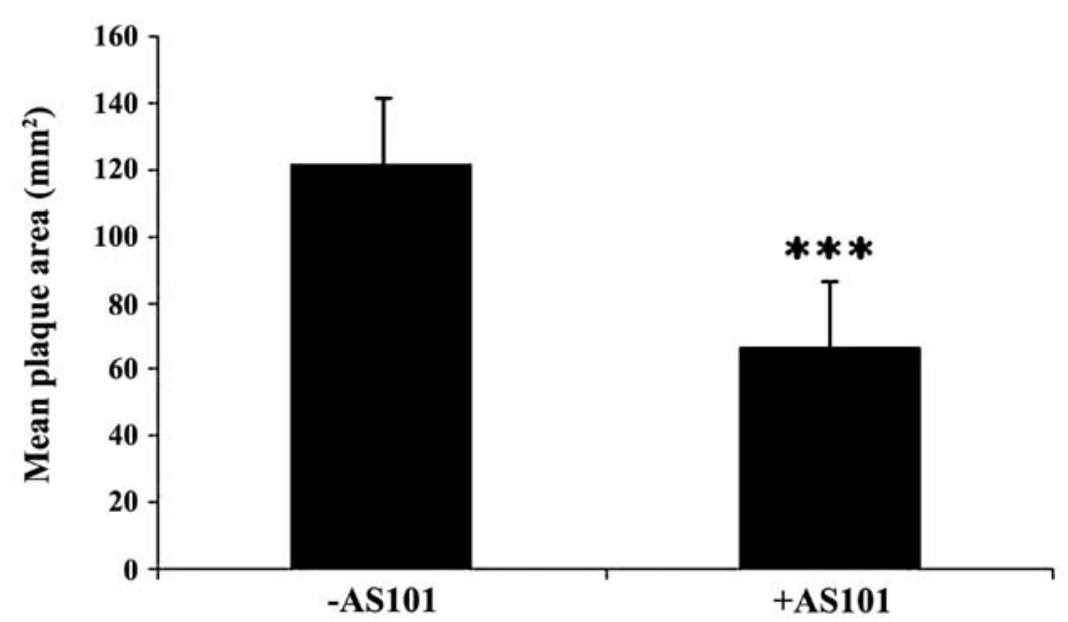

Figure 1. Effect of AS101 on plaque formation induced by herpes simplex virus (HSV)-1 and HSV-2. (A) Vero cells were infected with the HSV-1 VR strain, HSV-1 clinical isolate, the HSV-2 RL strain, or HSV-2 clinical isolate. AS101 (5 $\mu \mathrm{g} / \mathrm{ml})$ was added $1 \mathrm{~h}$ post-infection (pi). Cell cultures were fixed and stained on day 3 pi and photographed under a light table. (B) Graphic representation of the mean plaque area of 35 plaques of HSV-2 (RL) developed on Vero cells in the absence of AS101 and in the presence of $5 \mu \mathrm{g} / \mathrm{ml}$ AS101. Plaque area was calculated using ImageJ software. Each value represents the mean \pm standard deviation $(\mathrm{SD}) .{ }^{* * *} \mathrm{P}<0.001$.

HK cells were infected with 40-80 PFU of HSV-2, and AS101 was added post-infection at various concentrations. In another experimental setup, AS101 $(5 \mu \mathrm{g} / \mathrm{ml})$ was added $16 \mathrm{~h}$ prior to infection (pre-infection treatment) or it was added $16 \mathrm{~h}$ prior to infection and immediately post-infection (pre- + post-treatment). Following 4 days of incubation, the cells were fixed and stained. AS101 inhibited HSV-2 replication in the HK cells in a dose-dependent manner. The addition of the drug immediately post-infection was as effective as the addition of the drug at the time of infection and thereafter (pre- + post-treatment), while pre-treatment of the cells only prior to infection had a minor effect (Fig. 2). These experiments encouraged us to search in detail for the possible anti-viral activity of AS101 against HSV-1 and HSV-2 in our further experiments. An AS101 dose of $5 \mu \mathrm{g} / \mathrm{ml}$ was used for all further experiments with the HK cells. The Vero cells were used as an indicator cell line when titration of the virus progeny was required.

Effect of AS101 on HSV-2 yield production. The effect of AS101 on yield production was assessed by infecting the HK cells with either HSV-1 or HSV-2 at different MOI ratios. The titer of the virus progeny released into the supernatant was determined using plaque assay on the Vero cells. The administration of AS101 led to a $\geq 50 \%$ reduction in the HSV-1 yield and to an even more prominent effect (almost 2 log reduction) on the HSV-2 yield (Table II).

Effect of AS101 on the infectivity of mature HSV-1 and HSV-2. The effect of AS101 on the infectivity of mature cell-free viruses was examined by incubating a highly concentrated stock of the HSV-2 RL strain or HSV-1 strain (with AS101 at a final concentration of $5 \mu \mathrm{g} / \mathrm{ml}$, as described in the Materials and methods). No changes in viral infectivity were observed, indicating that AS101 exhibited no virucidal activity against HSV-1 or HSV-2 (Fig. 3). All the above results indicated that AS101 exhibited a significant anti-viral activity, specifically against HSV-2. For this reason, we decided to focus on the HSV-2 strain in our further explorations of the anti-viral mechanisms of AS101.

Effect of time of the addition of AS101 on HSV-2 propagation. In order to identify the stage of viral replication that is hindered 
A

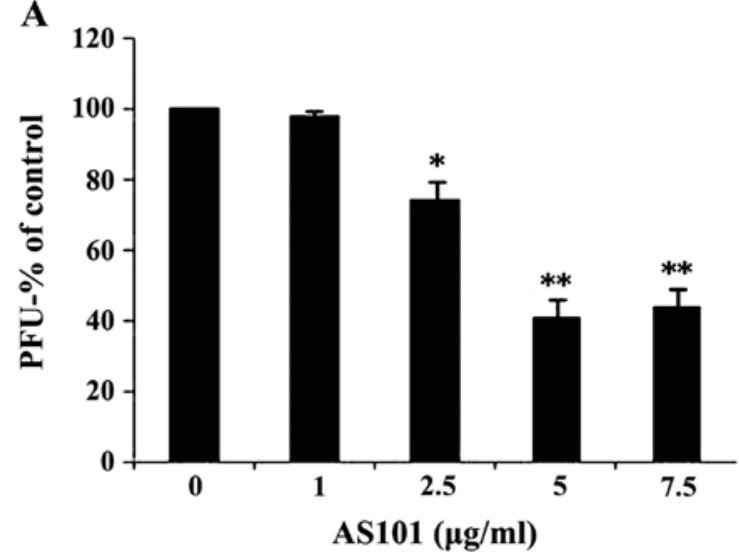

B

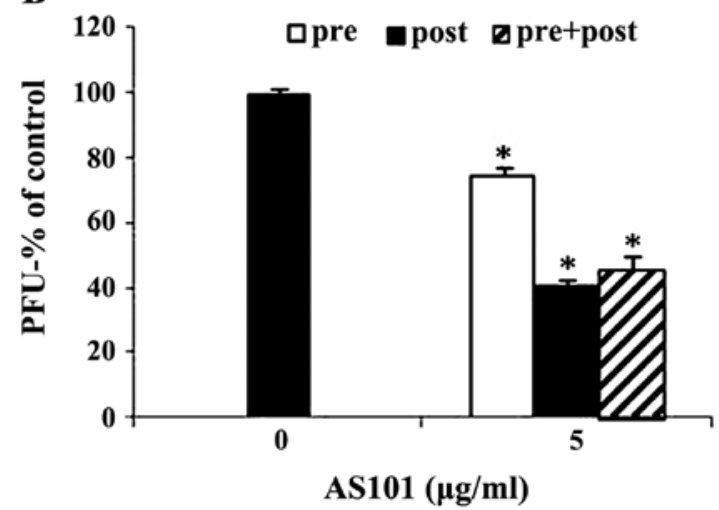

Figure 2. Effect of time of AS101 administration and AS101 concentration on herpes simplex virus 2 (HSV-2)-induced plaque formation in human kidney (HK) cells. (A) HK cells were infected with the HSV-2 strain. AS101 was added at the indicated concentrations at $1 \mathrm{~h}$ post-infection (pi). (B) HK cells were infected with the HSV-2 strain. AS101 $(5 \mu \mathrm{g} / \mathrm{ml})$ was added $16 \mathrm{~h}$ prior to infection and washed out prior to infection (pre-infection treatment), was present at the time of infection and thereafter (pre- + post-infection treatment), or added at $1 \mathrm{~h}$ pi. HK cells infected in the absence of AS101 served as the controls. Cell cultures were fixed and stained on day 3 pi. The percentage of plaque-forming units (PFU) of the control was calculated as follows: [(mean number of plaques in control - mean number of plaques in test)/mean number of plaques in control)] x100. Each test was performed in triplicate. Error bars represent the standard deviation $(\mathrm{SD})$ of the mean. ${ }^{*} \mathrm{P}<0.05,{ }^{* *} \mathrm{P}<0.01$.

by AS101, a synchronous infection in which AS101 was added from the onset of infection until titration or at various time points pi, was performed. In another experiment, AS101 was provided for the first $5 \mathrm{~h}$ of infection or, alternatively, was added at $5 \mathrm{~h}$ pi. The addition of AS101 within the first $9 \mathrm{~h}$ of infection inhibited viral replication to almost the same extent $(\sim 80 \%)$ as did treatment from the onset of infection (considered as $100 \%$ inhibition) (Fig. 4). In addition, when AS101 was present for the first $5 \mathrm{~h}$ of infection and then washed out of the system, its inhibitory effect was markedly reduced (Fig. 4B). When only administering AS101 at $3 \mathrm{~h}$ pi, approximately $20 \%$ of the anti-viral activity observed upon its administration at the onset of infection was lost, suggesting some effect on the early stages of replication. This minor effect on the early stages of replication was indistinguishable by the less sensitive plaque reduction assay (Fig. 2B).

Effect of AS101 on HSV-2 DNA synthesis and structural protein synthesis. The effect of AS101 on viral DNA synthesis
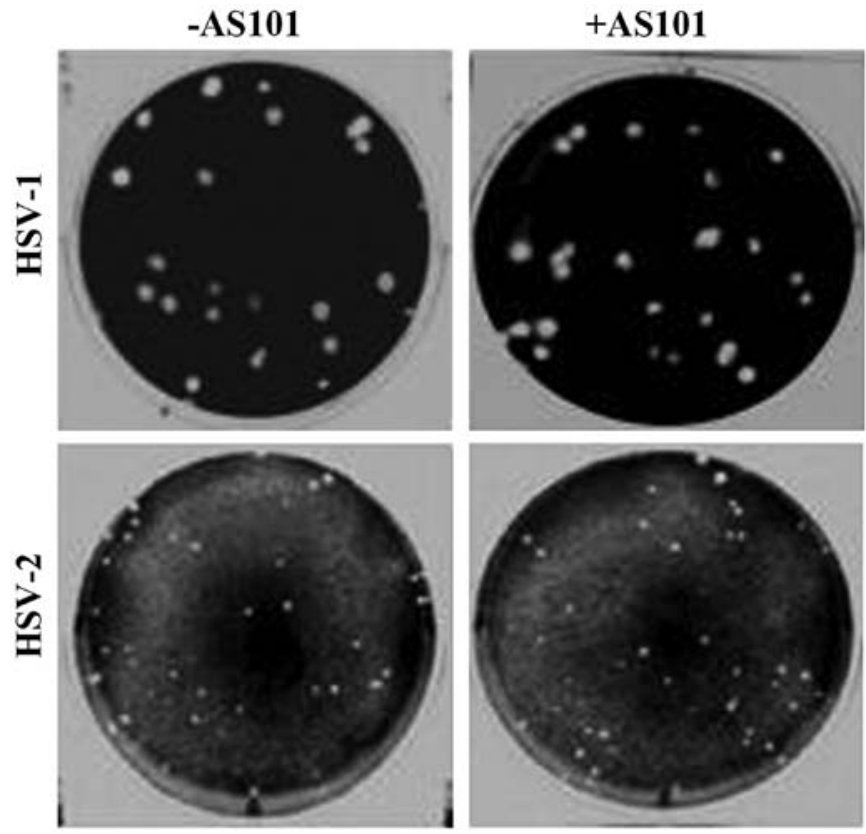

Figure 3. Effect of AS101 on the infectivity of mature herpes simplex virus (HSV)-1 and HSV-2. The HSV-1 VR strain and the HSV-2 RL strain were incubated at $37^{\circ} \mathrm{C}$ for $2 \mathrm{~h}$ with or without $5 \mu \mathrm{g} / \mathrm{ml}$ AS101. Immediately thereafter, treated viruses were diluted and used to infect Vero cells. Cultures were fixed and stained on day 3 post-infection. Images represent characteristic results out of several experiment repeats.

Table II. Effect of AS101 on HSV-1 and HSV-2 viral yield.

\begin{tabular}{|c|c|c|c|c|}
\hline Virus & MOI & $\begin{array}{c}\mathrm{AS} 101 \\
(5 \mu \mathrm{g} / \mathrm{ml})\end{array}$ & $\begin{array}{c}\log \\
(\mathrm{PFU} / \mathrm{ml})\end{array}$ & $\begin{array}{l}\text { Percentage } \\
\text { of inhibition }\end{array}$ \\
\hline \multirow[t]{8}{*}{ HSV-1 } & \multirow[t]{2}{*}{0.1} & - & $3.9 \pm 0.09$ & \multirow[t]{2}{*}{35} \\
\hline & & + & $3.7 \pm 0.08$ & \\
\hline & \multirow[t]{2}{*}{0.5} & - & $5.4 \pm 0.03$ & \multirow[t]{2}{*}{36} \\
\hline & & + & $5.1 \pm 0.04$ & \\
\hline & \multirow[t]{2}{*}{1} & - & $6.5 \pm 0.04$ & \multirow[t]{2}{*}{51} \\
\hline & & + & $6.2 \pm 0.07$ & \\
\hline & \multirow[t]{2}{*}{2} & - & \pm 0.028 .5 & \multirow[t]{2}{*}{47} \\
\hline & & + & \pm 0.068 .3 & \\
\hline \multirow[t]{8}{*}{ HSV-2 } & 0.1 & - & \pm 0.082 .3 & \multirow[t]{2}{*}{88} \\
\hline & & + & \pm 01.39 & \\
\hline & \multirow[t]{2}{*}{0.5} & - & $3.3 \pm 0.04$ & \multirow[t]{2}{*}{76} \\
\hline & & + & \pm 0.072 .7 & \\
\hline & \multirow[t]{2}{*}{1} & - & $3.34 \pm 0.01$ & \multirow[t]{2}{*}{97} \\
\hline & & + & $1.84 \pm 0.2$ & \\
\hline & \multirow[t]{2}{*}{2} & - & $6.1 \pm 0.1$ & \\
\hline & & + & $4.7 \pm 0.04$ & 96 \\
\hline
\end{tabular}

HSV-1, herpes simplex virus 1; HSV-2, herpes simplex virus 2; MOI, multiplicity of infection; PFU, plaque-forming units.

was evaluated in the culture supernatants and inside the cells by quantitative PCR. No significant effect on the genome copy number was observed in the presence of AS101 when measured 

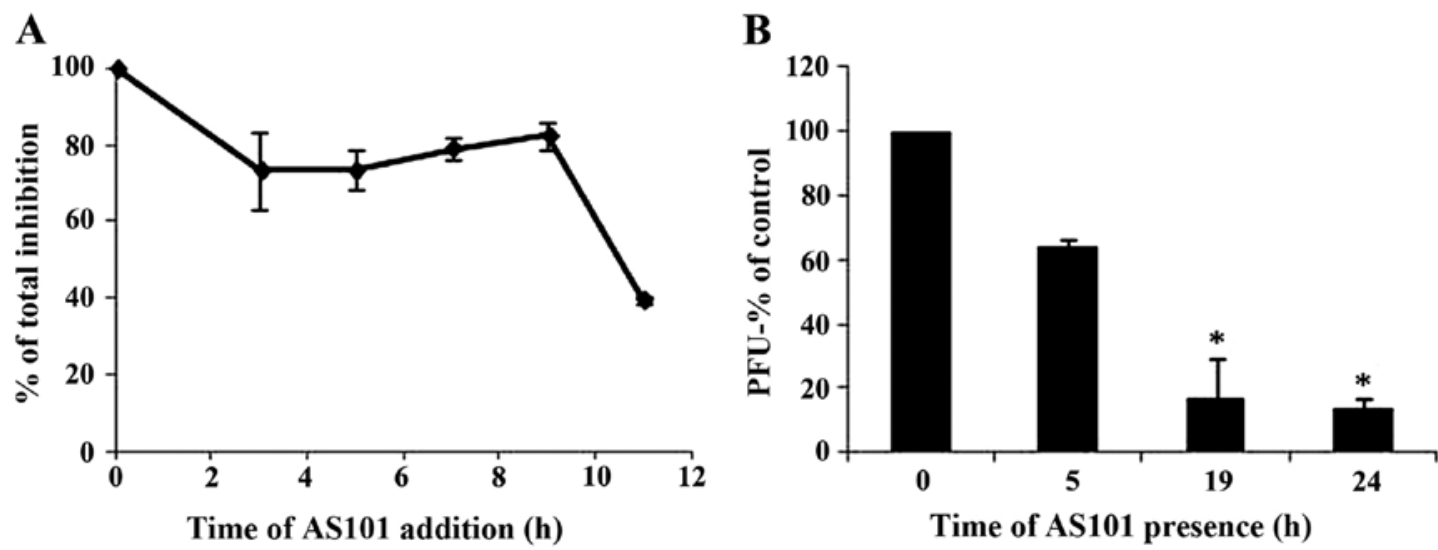

Figure 4. Effect of the time of AS101 addition on herpes simplex virus 2 (HSV-2) progeny yield. (A) Confluent human kidney (HK) cells were infected with HSV-2 [2 multiplicity of infection (MOI)]. AS101 $(5 \mu \mathrm{g} / \mathrm{ml})$ was added at different time points post-infection (pi). Infected, untreated cell culture served as the control. Time 0 is defined as the time of the additino of the virus. All treatments ended $24 \mathrm{~h}$ pi. Viral yield in plaque-forming units (PFU) was determined for all infected cultures. Viral yield at time 0 was considered as maximal inhibition (100\%). The percentage of reduction in viral inhibition compared to time 0 , was calculated for each time point. Each test was performed in triplicate. The error bar represents the mean \pm standard deviation (SD). (B) HK cells were infected with HSV-2 (2 MOI). AS101 was either administered for the first $5 \mathrm{~h}$ pi and then washed out, or was added $5 \mathrm{~h}$ pi until virus harvest at $24 \mathrm{~h}$ pi. Cells infected in the absence of the drug served as the control. Viral yield in plaque-forming units (PFU) was determined for each treatment and calculated as percentage of control. Each test was performed in triplicate. Data represent the means \pm standard deviation (SD). ${ }^{*} \mathrm{P}<0.05$.

from the cell culture medium or from inside the cells (Fig. 5A). Likewise, when assessing intracellular viral protein synthesis by the immunostaining of viral structural proteins, staining of the viral structural proteins was similar in the presence or absence of the compound (Fig. 5B).

Effect of AS101 on the infectivity of intracellular HSV-2. Since AS101 exerted an inhibitory effect on viral infectivity, we were interested in measuring the infectivity of intracellular viruses as well. Infectivity of both free and cell-associated viruses from the AS101-treated and -untreated HK cultures was determined using the plaque assay. The obtained results revealed that the infectivity of the extracellular virus was reduced by $2 \operatorname{logs}$ by AS101, while the infectivity of the intracellular virus was reduced by only $1 \log$ (Fig. 6).

\section{Discussion}

HSV infections are usually effectively treated with nucleoside analog drugs, such as acyclovir, or with DNA polymerase inhibitors, such as forscarnet or cidofovir (3). However, the appearance of thymidime kinase or DNA polymerase-mutated viruses, particularly among immunocompromised patients, renders these drugs inadequate in certain patient populations. Thus, compounds that can inhibit HSV replication by other mechanisms are urgently required $(5,21,22)$. The purpose of this study was to explore the anti-viral activity of AS101 against HSV. AS101 is an organotellurium compound that has been shown to exert anti-viral effects against a variety of human viruses $(16,17)$. A recent study demonstrated that AS101 can even eradicate genital warts attributed to HPV (18).

In this study, we demonstrated that AS101 exerted a significant anti-viral effect against HSV-2, but only a minor effect against HSV-1. When added post-adsorption, AS101 inhibited HSV-2induced plaque formation, as manifested by the reduced plaque size in the Vero cells and the reduced plaque number and viral yield in the HK cells (Figs. 1 and 2). The incubation of mature virions with AS101 did not alter the viral infectivity, suggesting that AS101 does not interact with mature viruses (Fig. 3). In an attempt to identify the stage of viral replication that is sensitive to the drug, we performed a kinetic assay in which AS101 was added at different time points post-infection. AS101 maintained $80 \%$ of its inhibitory capacity when added at up to $9 \mathrm{~h}$ pi, a time when viral DNA synthesis and nucleocapsid formation are already complete (23). These results are compatible with those demonstrating that AS101 did not interfere with either viral DNA or protein synthesis, as manifested by the equal genome copy numbers in the presence or absence of AS101 for both free and cell-associated viruses (Fig. 5). On the other hand, the titer of infective viruses that burst from infected cells was markedly lower (almost $2 \log$ reduction) in the presence of AS101, an effect that was most clearly demonstrated when the cells were infected with an MOI of 1 or 2 (Table II). Of note, the effect of AS101 on HSV-2 infectivity was reduced by $1 \log$ when we comparing the infectivity of HSV-2 liberated from inside the cells to that of HSV-2 found in the cell culture fluid without any intervention (Fig. 6). Considering that AS101 is not active against mature, cell-released viruses, and that drug uptake by the cells has not been established, these results suggest that AS101 mainly affects the complex process of viral egress, which takes place at the cell membrane, leading to the accumulation of defective viral particles.

The phenomenon of the reduction of plaque size in the presence of the drug may also result from an increase in the number of defective viral particles. Although most of the AS101 activity is exerted during the late stages of viral replication, kinetic assays revealed that $20-30 \%$ of the total anti-viral activity may be attributed to the early stages of replication. Viral entry and egress involve both cellular and viral proteins embedded in the cell membrane and in the viral membrane envelope. As reported in the literature, Te(IV) compounds readily interact with thiols to form a Te-S bond (11). It has already been shown that many of the AS101 biological activities are attributed to the ability of its tellurium ion to interact with a cysteine 
A
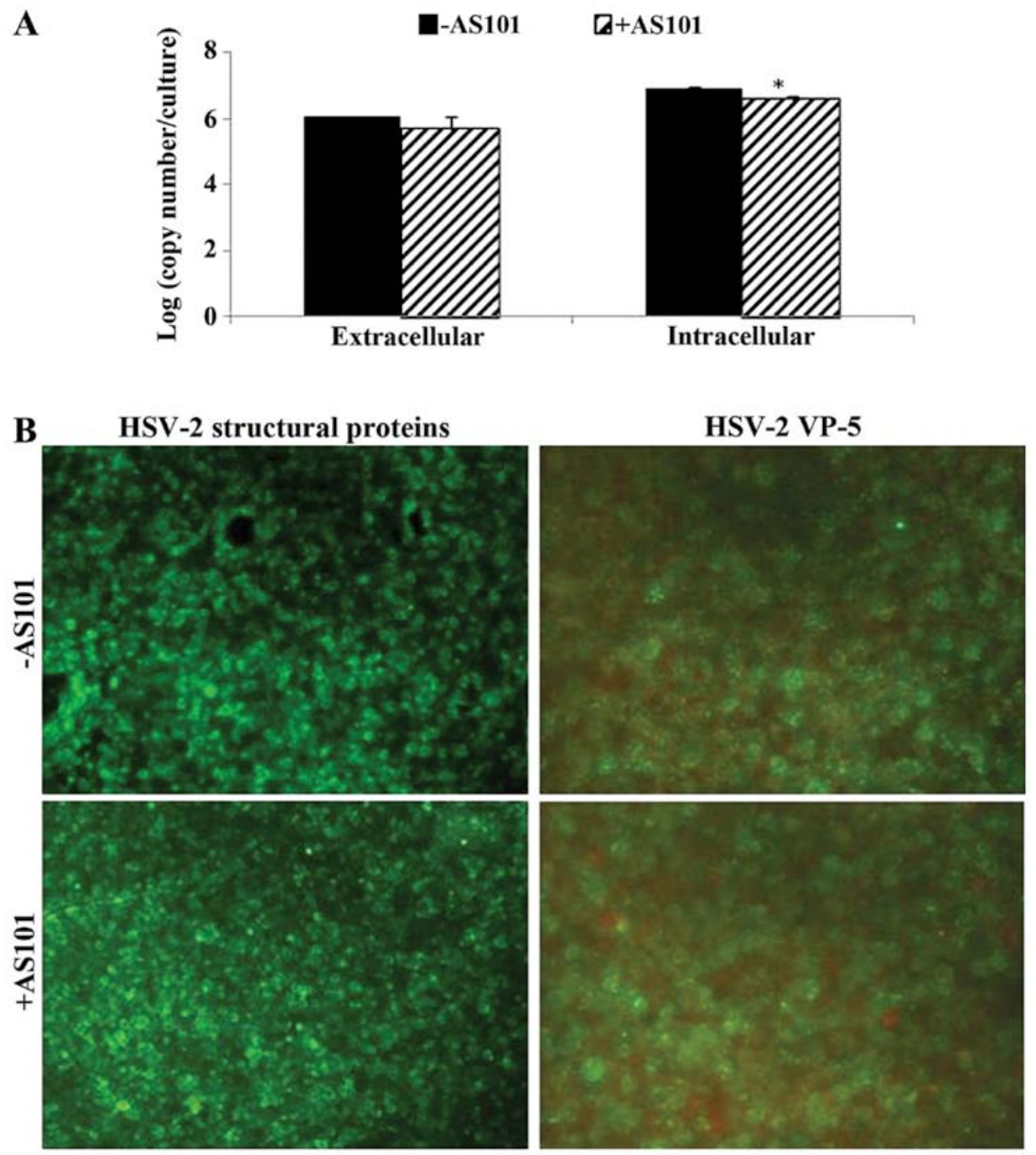

Figure 5. Effect of AS101 on herpes simplex virus 2 (HSV-2) DNA and protein synthesis. (A) Confluent human kidney (HK) cells were infected with HSV-2 [2 multiplicity of infection (MOI)]. AS101 $(5 \mu \mathrm{g} / \mathrm{ml})$ was added $1 \mathrm{~h}$ post-infection (pi). Free virus (supernatant) and cell-associated viruses were collected $24 \mathrm{~h}$ pi. DNA was extracted and genome copy number was quantitated by quantitative PCR. Data represent the means \pm standard deviation (SD). "P<0.05. (B) Confluent HK cells were infected with HSV-2 (2 MOI). AS101 $(5 \mu \mathrm{g} / \mathrm{ml})$ was added at $1 \mathrm{~h}$ pi. Twenty hours later, the cells were fixed with acetone and stained for HSV-2 structural proteins (left panel) or for HSV-2 VP-5 (right panel) by indirect and direct immunofluorescence staining, respectively.

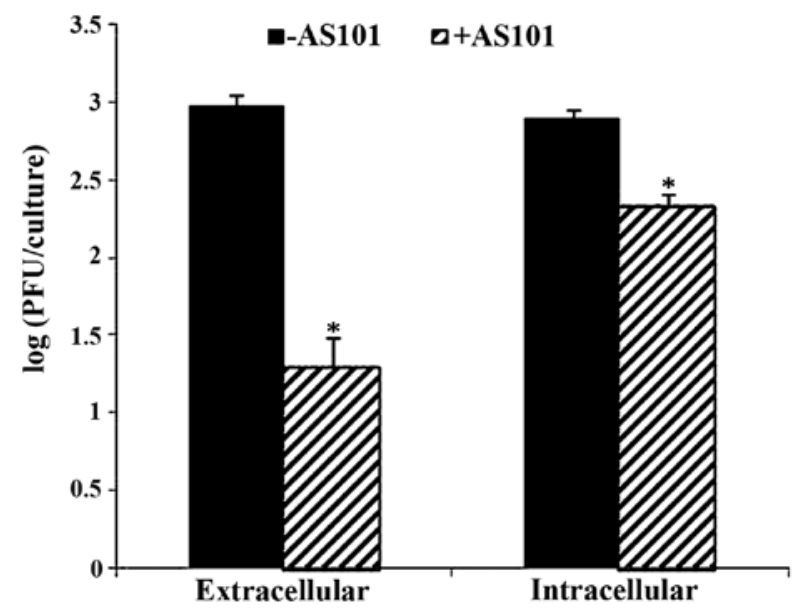

Figure 6. Effect of AS101 on the infectivity of intracellular and extracellular herpes simplex virus 2 (HSV-2) progeny. Human kidney (HK) cells were infected with HSV-2 [2 multiplicity of infection (MOI)]. AS101 $(5 \mu \mathrm{g} / \mathrm{ml})$ was added $1 \mathrm{~h}$ post-infection (pi). Free virus (supernatants) and cell-associated viruses were collected $24 \mathrm{~h}$ pi. Infectious viral titer was determined on Vero cells by the plaque assay. Each test was performed in triplicate. Data represent the means \pm standard deviation (SD). ${ }^{*} \mathrm{P}<0.05$. residue in the active site of proteins, thereby modifying their activity $(11,13,14)$. HSV has at least 12 membrane-associated glycoproteins (24) that play a pivotal role in viral penetration and egress, and are essential for viral infectivity $(25,26)$. For instance, glycoprotein D (gD) is a structural component of the HSV envelope that is essential for virus penetration, and its structure is dependent on maintenance of three intact disulfide bonds (17). The chemical properties of AS101 suggest that it reacts with cysteine residues on both viral and cellular glycoproteins. The differential anti-viral activity of AS101 against HSV-1, compared to HSV-2, can also be derived from diversity in cysteine content and function among the two HSV types (17).

A recently published study provided evidence that AS101 may inhibit WNV entry into Vero cells by interacting with a putative host-cell receptor of the WNV $\alpha(\mathrm{V}) \beta(3)$ integrin (17). Other studies have demonstrated that $\alpha(\mathrm{V}) \beta(3)$ integrin is a determinant in the choice of the HSV entry pathway into cells (27), and that HSV-1 glycoprotein $\mathrm{H}(\mathrm{gH})$ can bind to cells using the $\alpha(\mathrm{V}) \beta(3)$ integrin (28). Therefore, the blocking of $\alpha(\mathrm{V}) \beta(3)$ integrin by AS101 may partially account for 
its minor activity at the early stages of viral replication. In their comprehensive analysis of HSV egress from Vero cells, Mingo et al (29) demonstrated that HSV was released in specific pocket-like areas on the plasma membrane that coincided with the substrate-adherent surface and cell-cell-adherent contact points (29). Integrins are located at the very same points (29); an association between AS101 and these molecules may interrupt the delicate membrane structure and interfere with the release of the virus in a manner that leads to the formation of defective viral particles.

HSV, similar to HPV, triggers the formation of dermal lesions. The efficacy of an AS101 cream will be simple to test on lesions in vaginally HSV-2-infected female mice (30). In addition, AS101 was found to be active when added at late time points post-infection and, hence, can be considered a therapeutic agent and not a prophylactic drug. One major obstacle in the possible future use of AS101 as an anti-herpetic remedy is its limited effectiveness against HSV-1. Therefore, a compound that will synergize with AS101 in its anti-viral activity against HSV-1 is necessary. Indeed a molecule known as cysteamine was found to synergize the effect of AS101 as a growth inhibitor of Jurkat cells (31). In our future research, we aim to focus on studying the anti-viral activity of the combination of AS101 with cysteamine, and on conducting in vivo experiments for further evaluation of the AS101 anti-viral activity against herpes viruses.

\section{Acknowledgements}

This study was supported by the Israeli Ministry of Health. We wish to thank Dr S. Soupaev and Dr M. Book for their helpful advice and Dr J. Alfandri and Dr Z. Cohen for generously providing technical support in the laboratory. This study was part of the Master's thesis of Ms. Danna Sheinboim.

\section{References}

1. Wilson C: Reproductive endocrinology: AS101 might prevent chemotherapy-induced infertility. Nat Rev Endocrinol 9: 441, 2013.

2. Rowe AM, St Leger AJ, Jeon S, Dhaliwal DK, Knickelbein JE and Hendricks RL: Herpes keratitis. Prog Retin Eye Res 32: 88-101, 2013

3. Rozenberg F, Deback C and Agut H: Herpes simplex encephalitis: From virus to therapy. Infect Disord Drug Targets 11: 235-250, 2011.

4. Taylor TJ, Brockman MA, McNamee EE and Knipe DM: Herpes simplex virus. Front Biosci 7: d752-d764, 2002.

5. Piret J and Boivin G: Resistance of herpes simplex viruses to nucleoside analogues: Mechanisms, prevalence, and management. Antimicrob Agents Chemother 55: 459-472, 2011.

6. Zhang Y, But PP, Ooi VE, Xu HX, Delaney GD, Lee SH and Lee SF: Chemical properties, mode of action, and in vivo anti-herpes activities of a lignin-carbohydrate complex from Prunella vulgaris. Antiviral Res 75: 242-249, 2007.

7. Yarmolinsky L, Zaccai M, Ben-Shabat S, Mills D and Huleihel M: Antiviral activity of ethanol extracts of Ficus binjamina and Lilium candidum in vitro. N Biotechnol 26: 307-313, 2009.

8. Bernstein DI, Miller RL and Harrison CJ: Effects of therapy with an immunomodulator (imiquimod, R-837) alone and with acyclovir on genital HSV-2 infection in guinea-pigs when begun after lesion development. Antiviral Res 20: 45-55, 1993.

9. Abad MJ, Guerra JA, Bermejo P, Irurzun A and Carrasco L: Search for antiviral activity in higher plant extracts. Phytother Res 14: 604-607, 2000.

10. Hirokawa D, Woldow A, Lee SN and Samie F: Treatment of recalcitrant herpes simplex virus with topical imiquimod. Cutis 88 : 276-277, 2011.
11. Albeck A, Weitman H, Sredni B and Albeck M: Tellurium compounds: Selective Inhibition of cysteine proteases and model reaction with thiols. Inorg Chem 37: 1704-1712, 1998.

12. Halperin-Sheinfeld M, Gertler A, Okun E, Sredni B and Cohen HY: The Tellurium compound, AS101, increases SIRT1 level and activity and prevents type 2 diabetes. Aging (Albany NY) 4: 436-447, 2012.

13. Sredni B, Geffen-Aricha R, Duan W, Albeck M, Shalit F, Lander HM, Kinor N, Sagi O, Albeck A, Yosef S, et al: Multifunctional tellurium molecule protects and restores dopaminergic neurons in Parkinson's disease models. FASEB J 21: 1870-1883, 2007.

14. Sredni B, Gal R, Cohen IJ, Dazard JE, Givol D, Gafter U, Motro B, Eliyahu S, Albeck M, Lander HM, et al: Hair growth induction by the Tellurium immunomodulator AS101: Association with delayed terminal differentiation of follicular keratinocytes and ras-dependent up-regulation of KGF expression. FASEB J 18: 400-402, 2004.

15. Sredni B, Rosenthal-Galili Z, Michlin H, Sobelman D, Seger Y, Blagerman S, Kalechman Y and Rager-Zisman B: Restoration of murine cytomegalovirus (MCMV) induced myelosuppression by AS101. Immunol Lett 43: 159-165, 1994.

16. Vonsover A, Loya S, Sredni B, Albeck M, Gotlieb-Stematsky T, Araf $\mathrm{O}$ and Hizi A: Inhibition of the reverse transcriptase activity and replication of human immunodeficiency virus type 1 by AS101 in vitro. AIDS Res Hum Retroviruses 8: 613-623, 1992.

17. Indenbaum V, Bin H, Makarovsky D, Weil M, Shulman LM, Albeck M, Sredni B and Mendelson E: In vitro and in vivo activity of AS101 against West Nile virus (WNV). Virus Res 166: 68-76, 2012.

18. Friedman M, Bayer I, Letko I, Duvdevani R, Zavaro-Levy O, Ron B, Albeck M and Sredni B: Topical treatment for human papillomavirus-associated genital warts in humans with the novel tellurium immunomodulator AS101: Assessment of its safety and efficacy. Br J Dermatol 160: 403-408, 2009.

19. Cantatore A, Randall SD, Traum D and Adams SD: Effect of black tea extract on herpes simplex virus-1 infection of cultured cells. BMC Complement Altern Med 13: 139, 2013.

20. Filén F, Strand A, Allard A, Blomberg J and Herrmann B: Duplex real-time polymerase chain reaction assay for detection and quantification of herpes simplex virus type 1 and herpes simplex virus type 2 in genital and cutaneous lesions. Sex Transm Dis 31: 331-336, 2004.

21. Snoeck R: Antiviral therapy of herpes simplex. Int J Antimicrob Agents 16: 157-159, 2000.

22. Wilson SS, Fakioglu E and Herold BC: Novel approaches in fighting herpes simplex virus infections. Expert Rev Anti Infect Ther 7: 559-568, 2009.

23. Koyama AH and Uchida T: Quantitative studies on the maturation process of herpes simplex virus type 1 in Vero cells. Virus Res 10: 281-285, 1988.

24. Norais N, Tang D, Kaur S, Chamberlain SH, Masiarz FR, Burke RL and Marcus F: Disulfide bonds of herpes simplex virus type 2 glycoprotein gB. J Virol 70: 7379-7387, 1996.

25. Foster TP and Kousoulas KG: Genetic analysis of the role of herpes simplex virus type 1 glycoprotein $\mathrm{K}$ in infectious virus production and egress. J Virol 73: 8457-8468, 1999.

26. Foster TP, Chouljenko VN and Kousoulas KG: Functional and physical interactions of the herpes simplex virus type 1 UL20 membrane protein with glycoprotein K. J Virol 82: 6310-6323, 2008.

27. Gianni T and Campadelli-Fiume G: $\alpha V \beta 3$-integrin relocalizes nectin1 and routes herpes simplex virus to lipid rafts. J Virol 86: 2850-2855, 2012

28. Parry C, Bell S, Minson T and Browne H: Herpes simplex virus type 1 glycoprotein $\mathrm{H}$ binds to alphavbeta3 integrins. J Gen Virol 86: 7-10, 2005.

29. Mingo RM, Han J, Newcomb WW and Brown JC: Replication of herpes simplex virus: Egress of progeny virus at specialized cell membrane sites. J Virol 86: 7084-7097, 2012.

30. Ikeda K, Yamasaki H, Minami S, Suzuki Y, Tsujimoto K, Sekino Y, Irie H, Arakawa T and Koyama AH: Arginine inactivates human herpesvirus 2 and inhibits genital herpesvirus infection. Int J Mol Med 30: 1307-1312, 2012.

31. Daniel-Hoffmann M, Albeck M, Sredni B and Nitzan Y: A potential antimicrobial treatment against ESBL-producing Klebsiella pneumoniae using the tellurium compound AS101. Arch Microbiol 191: 631-638, 2009. 